Tropical Journal of Pharmaceutical Research July 2017; 16 (7): 1601-1608

ISSN: $1596-5996$ (print); 1596-9827 (electronic)

(c) Pharmacotherapy Group, Faculty of Pharmacy, University of Benin, Benin City, 300001 Nigeria.

All rights reserved.

Available online at http://www.tjpr.org

Original Research Article

http://dx.doi.org/10.4314/tjpr.v16i7.19

\title{
Mitigation of monocyte inflammation by inhibition of sodium phosphate co-transporter with phosphonoformic acid and parthenolide in diabetic nephropathy uremia
}

\author{
Wei $\mathrm{Yu}^{1}$, Ruolan $\mathrm{Hu}^{2}$, Yan $\mathrm{Zhuo}^{3 *}$ and Ya Yang ${ }^{4}$ \\ ${ }^{1}$ Department of Nephrology, People's Hospital of Chongqing, ${ }^{2}$ Department of Respiratory, Chongqing Emergency Medical \\ Center, Chongqing, 400014, ${ }^{3}$ Department of Kidney, ${ }^{4}$ Department of Pharmacy, Southwest Hospital of Third Military Medical \\ University, Chongqing, 400038, China
}

*For correspondence: Email: yanzhuo2003@163.com

Sent for review: 8 April 2017

Revised accepted: 24 June 2017

\begin{abstract}
Purpose: To investigate the effect of sodium phosphate co-transporter (Pit-1) on the regulation of monocyte inflammation in diabetic nephropathy uremia (DNU) patients and the underlying principles of inflammatory immune response during DNU pathogenesis.

Methods: The levels of $C D 14^{+} C D 16^{+}$and Pit-1 on peripheral blood mononuclear cells (PBMC) were measured by flow cytometry. Serum C-reactive protein $(\mathrm{CRP})$ and $25(\mathrm{OH}) \mathrm{D}_{3}$ were detected by immunoturbidimetry while IL-6 and MCP-1 were assayed with enzyme-linked immunoassay (ELISA). The amounts of vitamin D receptors (VDRs) and Pit-1 mRNA in human acute monocytic leukemia cell lines (THP-1) were determined by quantitative real-time polymerase chain reaction (qRT-PCR), while western blot was utilized for measurement of NF-KB p65 and p-STAT5.

Results: Compared to the healthy group, DNU patients showed markedly higher $C D 14^{+} C D 16^{+}$, Pit-1, CRP, IL-6 and MCP-1, while 25(OH) $D_{3}$ was reduced. Following stimulation with PFA or PTN, comparison with DNU group revealed that THP-1 monocytes showed a significant down-regulation of Pit-1 (1.34 \pm 0.06 for PFA; $1.60 \pm 0.25$ for PTN; $p<0.05)$; NF-KB p65 (2.65 \pm 0.25 for PFA; $3.88 \pm 0.13$ for PTN; $p<0.01)$, p-STAT5 (2.49 \pm 0.10 for PFA; $3.03 \pm 0.09$ for PTN; $p<0.01)$ and a significant decrease in levels of IL-6 (55.38 \pm 3.22 for PFA, $68.68 \pm 6.01$ for PTN; $p<0.05)$; MCP-1 $39.67 \pm 3.62$ for PFA; $52.62 \pm 5.00$ for PTN; $p<0.01)$, except for VDR (0.64 \pm 0.15 for PFA, $0.43 \pm 0.03$ for PTN; $p<$ $0.05)$.

Conclusion: The level of expression of Pit-1 has a positive correlation with the level of inflammatory monocytes, which indicates that Pit-1 can be used as a new biomarker for DNU diagnosis. In addition, since Pit-1 is connected to NF-KB and STAT5 signaling pathways which are critical to inflammatory immune response, development of drugs that target Pit-1 could be an approach in developing new strategies for DNU therapy.
\end{abstract}

Keywords: Pit-1, Diabetic nephropathy, Uremia, Monocytes, Inflammation, NF-KB, STAT5

Tropical Journal of Pharmaceutical Research is indexed by Science Citation Index (SciSearch), Scopus, International Pharmaceutical Abstract, Chemical Abstracts, Embase, Index Copernicus, EBSCO, African Index Medicus, JournalSeek, Journal Citation Reports/Science Edition, Directory of Open Access Journals (DOAJ), African Journal Online, Bioline International, Open-J-Gate and Pharmacy Abstracts

\section{INTRODUCTION}

Diabetic nephropathy (DN), one of complications of diabetes mellitus (DM) plays a pivotal role in the development of end-stage renal disease, which severely threatens the life of the sufferer
$[1,2]$. DN always progresses into uremia, which is clinically described as diabetic neuropathy uremia (DNU). Therefore, there is the need for further studies on DN prevention and treatment. Recent evidence has demonstrated that inflammatory responses mediated by cytokines 
participate in DN progression [3,4]. The pathological mechanisms of DN development are currently believed to be associated with chronic infection, genetic mutations, up-regulation of macrophage migration inhibitors and proinflammatory monocytes [5]. However, the mechanism by which the presence inflammatory monocytes in DNU is triggered remains largely unclear.

Pit-1, type I of sodium-dependent phosphate transporter, NaPi-III, which belongs to the group of housekeeping proteins, maintains cell metabolism, signal transduction and nucleic acid and phospholipid synthesis by phosphorus uptake [6]. A large number of animal and cell experiments have revealed that Pit- 1 is involved in vascular calcification of DNU patients [7]. However, there is paucity of information on whether Pit-1 participates in the stimulation of inflammatory monocytes in DNU patients or not, and how it does it.

This study examined the effects of Pit- 1 on inflammatory response of monocytes in DNU patients. Its effects on the activities of NF-KB p65 and PSTAT5 were investigated in the hope that the findings will lead to an understanding of the role of NF-KB and STAT5 in the progression of $\mathrm{DN}$ to $\mathrm{DNU}$.

\section{EXPERIMENTAL}

\section{Patient selection}

All those who volunteered to be subjects in this study are Chinese Han but not biologically related. The healthy group included 10 males and 10 females with no history of DM, kidney disease, coronary heart disease, hypertension and other metabolic disorders, while the DNU group without dialysis consisted of 20 females and 20 males with urinary albumin excretion > $300 \mathrm{mg} / 24 \mathrm{~h}[5]$.

Diagnosis of DNU followed WHO Diagnostic Criteria and Classification of Diabetes Mellitus 1998 [8] and Kidney Disease Outcomes Quality Initiative 2012 [9]. The experimental protocol was approved by the Ethics Review Board of Southwest Hospital, Third Military Medical University (ref no. 2013-23) and followed the guidelines of Helsinki Declaration [10].

\section{PBMCs isolation}

After an $8 \mathrm{~h}$ fasting period, blood samples were taken from each subject with hypodermic syringe and put in appropriately labeled heparinized tubes and the plasma samples obtained used for biochemical tests. PBMCs, isolated by density gradient centrifugation, were washed in nonserum 1640 culture medium (GIBCO, USA), resuspended in RPMI-1640 (GIBCO, USA) containing $10 \%(\mathrm{v} / \mathrm{v})$ heat-inactivated $\mathrm{FCS}, 50$ $\mathrm{U} / \mathrm{mL}$ penicillin as well as $50 \mathrm{mg} / \mathrm{mL}$ streptomycin. Thereafter, the monocytes were cultured in a 96-well plate at a cell density of $1 \times 10^{6}$ per well and maintained at $37.0^{\circ} \mathrm{C} / 5 \%$ $\mathrm{CO}_{2}$. After collection of supernatants and THP-1 monocytes, peripheral plasma samples were treated with phosphonoformic acid (PFA) or parthenolide (PTN) at $1 \mu \mathrm{g} / \mathrm{mL}$ for $24 \mathrm{~h}$. THP-1 monocytes used in this study were obtained as a gift from the Cell Bank of Chinese Academy of Sciences. THP-1 monocytes are excellent for use in place of mononuclear macrophages for the study of the function and status of the latter in vitro.

\section{Flow cytometry analysis of monocytes and Pit-1}

Peripheral blood was pretreated with EDTA and then transferred to flow cytometry tubes (150 $\mu \mathrm{L})$, followed by the addition of 10 microlitres each of CD14-PE, CD16-FITC and Pit-1-FITC (AbD Serotec, UK) into appropriately identified tubes. At the same time, corresponding tubes with identical contents but without fluorescent antibody were set up as blank controls. Flow cytometry samples were incubated at room temperature for $30 \mathrm{~min}$ without light, supplemented with $1 \mathrm{~mL}$ erythrocyte lysis buffer and mixed well for $5 \mathrm{~min}$. Cells, harvested in 1 $\mathrm{mL}$ PBS containing $1 \%$ BSA were centrifuged at $1600 \mathrm{rpm}$ for $10 \mathrm{~min}$ and the supernatants discarded. The packed cells were rinsed twice before fixing them in paraformaldehyde for 10 min. Mean fluorescent intensities (MFI) of $\mathrm{CD}_{14}{ }^{+} \mathrm{CD} 16^{+}$and Pit-1 were measured with a FACS-Calibur flow cytometer following the manufacturers' instructions (Becton Dickinson, USA).

\section{Immunoturbidimetry measurement of 25(OH) $\mathrm{D}_{3}$ and CRP}

Serum $25(\mathrm{OH}) \mathrm{D}_{3}$ and $\mathrm{CRP}$ were measured by latex particle-enhanced immunoturbidimetry (Shanghai Biotechnology, China), according to the manufacturers' protocol.

\section{Determination MCP-1 and IL- 6 by ELISA}

After appropriate treatments, serum MCP-1 and IL-6 were measured by ELISA kit (Takara, Japan). Each experiment was carried out in triplicate. 


\section{qRT-PCR for VDR and Pit-1}

After $24 \mathrm{~h}$ treatment with PFA or PTN, cells were collected for RNA extraction using SV Total RNA Isolation System (Promega, USA) while TURBO DNA-free ${ }^{\text {TM }}$ Kit (Ambion, USA) was used to remove DNA contamination. The products of reverse transcription were obtained using $S Y B R^{\circledR}$ PrimeScript ${ }^{\mathrm{TM}} \mathrm{RT}$ reagent Kit (Takara, Kusatsu, Japan) according to the recommendation of the manufacturer. The reverse transcription process was performed in a 384-wall plate for real-time quantitative PCR using the LightCycler ${ }^{\circledR} 480$ system (Roche, Switzerland). Each PCR event was repeated at least 3 times.

\section{Western blot analysis p-STAT5 and NF-KB p65}

Cells were harvested and lysed after PFA or PTN treatment for $24 \mathrm{~h}$, and the lysate was centrifuged at $12,000 \mathrm{rpm}$ at $4{ }^{\circ} \mathrm{C}$ for $10 \mathrm{~min}$. Proteins in cytoplasm and nuclei, prepared for western blot analysis, were isolated by Extraction Kit according to manufacturer's instructions (Thermo Fisher Scientific, USA). Protein concentration in supernatant was measured with BCA assay kit (Thermo Fisher Scientific, USA). Sample was mixed with $6 \times$ loading buffer and denatured at $100{ }^{\circ} \mathrm{C}$ for $5 \mathrm{~min}$. After separation by $12 \%$ SDS-PAGE, $30 \mu \mathrm{g}$ of each sample was transferred to PVDF membranes, and then blocked by $5 \%$ free-fat milk in TBST at RT for 1 h. Next, the membranes were incubated with specific primary antibodies (Santa Cruz Biotechnology, USA) against NF-KB p65 (1: $3,000)$, p-STAT5 $(1: 2,000)$, or GAPDH $(1: 5,000)$ at $4{ }^{\circ} \mathrm{C}$ overnight. HRP-labeled secondary goat anti-rabbit antibody $(1: 3,000)$ was used at RT for $2 \mathrm{~h}$. Following three washes in TBST, the membranes were treated with ECL (Thermo Fisher Scientific, USA) and exposed to x-ray films. Image J1.41p software ( $\mathrm{NIH}$, USA) was used for quantification.

\section{Statistical analysis}

Statistical analysis was carried out with SPSS 13.0. All results are presented as mean \pm SD. Data for multiple comparisons was analyzed by one-way ANOVA, followed by Dunnett's test. $P<$ 0.05 was considered statistically significant.

\section{RESULTS}

\section{Analysis on MFI of CD14 ${ }^{+} \mathrm{CD} 16^{+}$and Pit-1 in monocytes}

To determine whether the expression of Pit- 1 is relevant to local inflammation in DNU patients,
CD $14^{+} \mathrm{CD} 16^{+}$and Pit-1 levels in monocytes from normal control and DNU group were evaluated. As shown in Figure $1, \mathrm{CD} 14^{+} \mathrm{CD} 16^{+} \mathrm{MFI}$ was significantly higher in DNU group $(p<0.01)$ and Pit-1 MFI in monocytes from DNU patients was higher when compared to healthy control $(p<$ 0.05).

\section{Serum CRP, 25(OH) $D_{3}, M C P-1$ and IL-6}

Table 1 shows that CRP was significantly higher in the sera of DNU patients than in those of the healthy subjects (healthy subjects $1.49 \pm 0.35$ $\mathrm{mg} / \mathrm{ml}$, DNU group $5.31 \pm 1.34(\mathrm{mg} / \mathrm{ml}) ; p<0.01)$ while $25(\mathrm{OH}) \mathrm{D}_{3}$ in $\mathrm{DNU}$ patients was lower compared to normal control (healthy subjects $42.12 \pm 8.18 \mathrm{ng} / \mathrm{ml}$, DNU group $23.17 \pm 6.19$ $\mathrm{ng} / \mathrm{ml} ; p<0.05)$. The results also revealed that IL-6 (healthy subjects $11.67 \pm 2.95 \mathrm{pg} / \mathrm{m}$, DNU group $81.00 \pm 15.30 \mathrm{pg} / \mathrm{m} ; p<0.01$ ) and MCP-1 (healthy subjects $27.35 \pm 4.54 \mathrm{pg} / \mathrm{m}$, DNU group $56.02 \pm 5.93 \mathrm{pg} / \mathrm{m} ; p<0.01)$ from DNU group were significantly higher than that in healthy subjects. There was positive correlation between CRP concentration and those of MCP-1 and IL-6.

As shown in Figure 2, expression of Pit-1 was positively correlated with CRP concentration $(r=$ $0.695, p<0.01$, Figure 2A), IL-6 $(r=0.817, p<$ 0.01 , Figure $2 \mathrm{C})$ and MCP-1 $(r=0.824, p<0.01$, Figure 2D), but negatively correlated with $25(\mathrm{OH})$ $D_{3}(r=-0.794, p<0.01$, Figure. 2B).

\section{PFA and PTN inhibit Pit-1 expression}

In order to find out whether PFA and PTN could inhibit Pit-1, real-time quantitative PCR was used to examine Pit-1 in THP-1 monocytes incubated with serum from healthy subjects, DNU group, PFA-treated DNU group and PTN-treated DNU group. As shown in Figure 3A, when compared with healthy control, the expression level of Pit-1 was slightly higher in PFA treated group, markedly increased in PTN treated group, but significantly up-regulated in DNU group. It has been reported that lack of VDR is associated with the occurrence of $\mathrm{DN}$ and its complications. Therefore, changes in VDR levels were investigated. The results show that the expression level of VDR was exactly opposite to that of Pit-1 (Figure 3B).

\section{Suppression of STAT5 and NF-KB activities by PFA and PTN}

Two leading signaling pathways NF-kB and STAT5, are closely involved in inflammatory regulation [11]. In order to elucidate the mechanism of pro-inflammation regulation effect of Pit-1, 


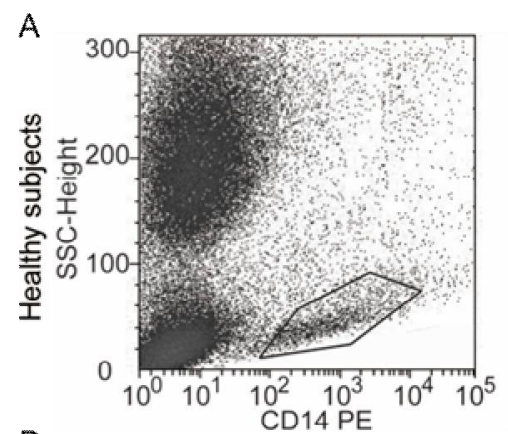

B


G

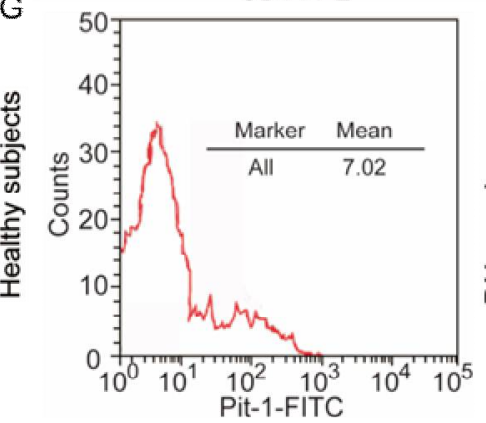

E
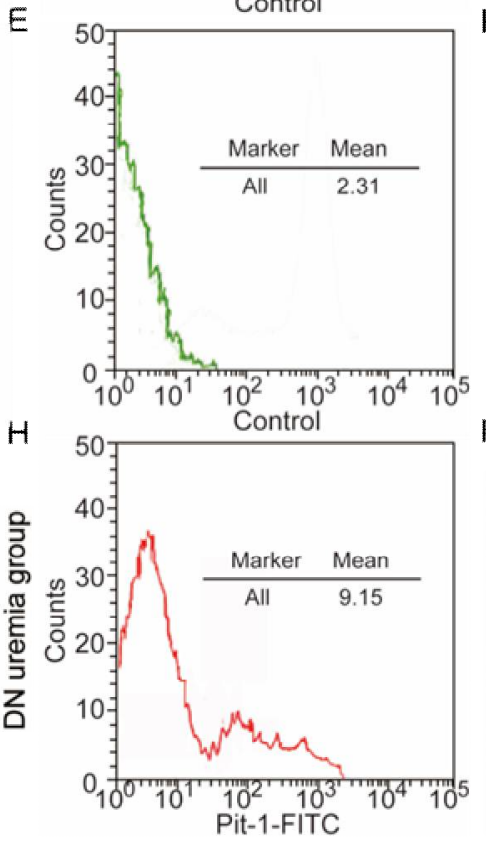

C

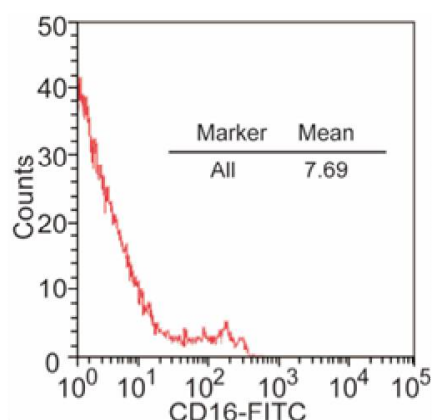

$F$
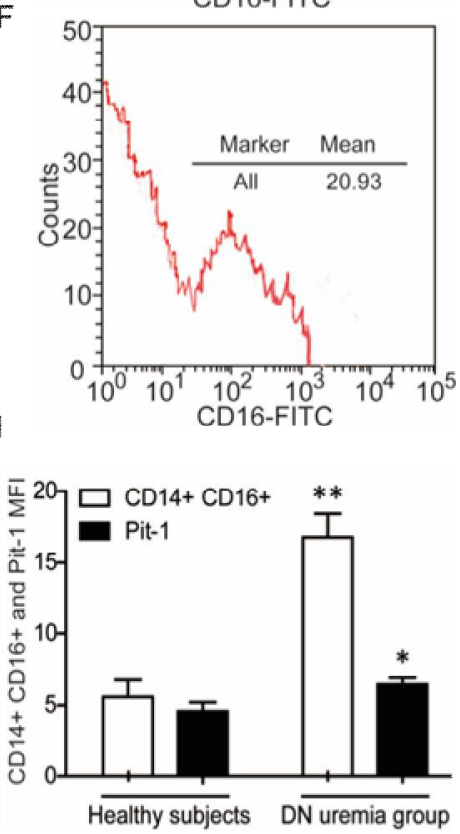

Figure 1: MFI of $C D 14^{+} C D 16^{+}$and Pit-1 in monocytes $(A, B, C, G)$ Healthy subjects; $(D, E, F, H)$ DN uremic patients; flow cytometry analysis MFIs of (AD) A FSC/SSC dot plot displaying monocytes identification; (BE) Green lines refer to control antibody staining; (CF) Curve of CD16 expression in $\mathrm{CD}^{+} 4^{+}$(GH) Curve of Pit-1 expression in $\mathrm{CD} 14^{+}$; (I) Statistical of $\mathrm{CD}^{+} 6^{+}$and Pit-1expression in $\mathrm{CD} 14^{+}$monocytes from 2 groups. CD14 ${ }^{+} \mathrm{CD} 16^{+} \mathrm{MFI}=\mathrm{C} / \mathrm{B}$ or F/E; Pit-1 MFI=G/B or H/E; ${ }^{*} p<0.05,{ }^{* *} p$ $<0.01$ vs. healthy subjects

Table 1: Levels of inflammation related factors in serum

\begin{tabular}{lcccc}
\hline Group & $\begin{array}{c}\mathbf{2 5}(\mathbf{O H}) \text { VD3 } \\
(\mathbf{n g} / \mathbf{m l})\end{array}$ & $\begin{array}{c}\text { IL-6 } \\
(\mathbf{p g} / \mathbf{m l})\end{array}$ & $\begin{array}{c}\text { MCP-1 } \\
(\mathbf{p g} / \mathbf{m l})\end{array}$ & $\begin{array}{c}\text { CRP } \\
(\mathbf{m g} / \mathbf{m l})\end{array}$ \\
\hline Healthy subjects & $42.12 \pm 8.18$ & $11.67 \pm 2.95$ & $27.35 \pm 4.54$ & $1.49 \pm 0.35$ \\
DN uremia group & ${ }^{*} 23.17 \pm 6.19$ & ${ }^{* *} 81.00 \pm 15.30$ & ${ }^{* *} 56.02 \pm 5.93$ & ${ }^{* *} 5.31 \pm 1.34$ \\
\hline
\end{tabular}

${ }^{*} P<0.05,{ }^{* *} p<0.01$ vs. healthy subjects

Western blot was utilized to detect the phosphorylation level of NF-kB p65 as well as pSTAT5. The results are shown in Figure 4. Compared to healthy subjects, NF-KB p65 and pSTAT5 were markedly higher in DNU, PFA treated group and PTN treated group $(p<0.01)$. The phosphorylation levels of pSTAT5 and NFKB p65 in DNU patients were increased when compared with healthy subjects $(p<0.01)$. When compared with DNU group, the phosphorylation levels of pSTAT5 and NF-kB p65 were significantly lower in PFA treated and PTN treated $(p<0.01)$.

\section{Attenuation of inflammatory cytokines expressions in THP-1 via PFA and PTN}

IL-6 and MCP-1 are recognized as important cytokines of the inflammatory state that is considered to be associated with DN. To confirm whether inhibition of Pit-1 could alleviate 
A

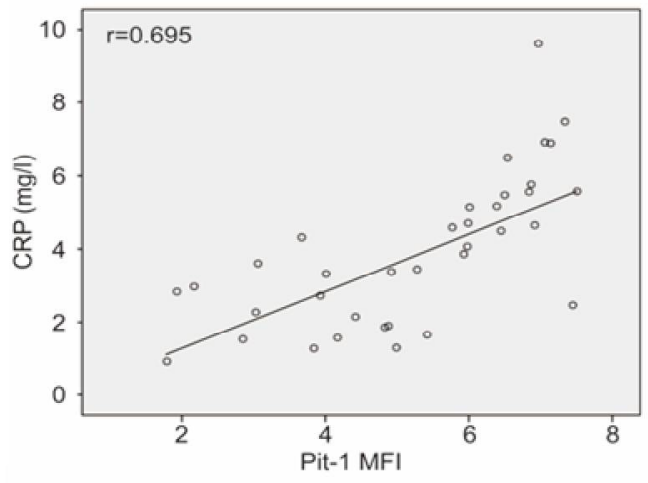

$\mathrm{C}$

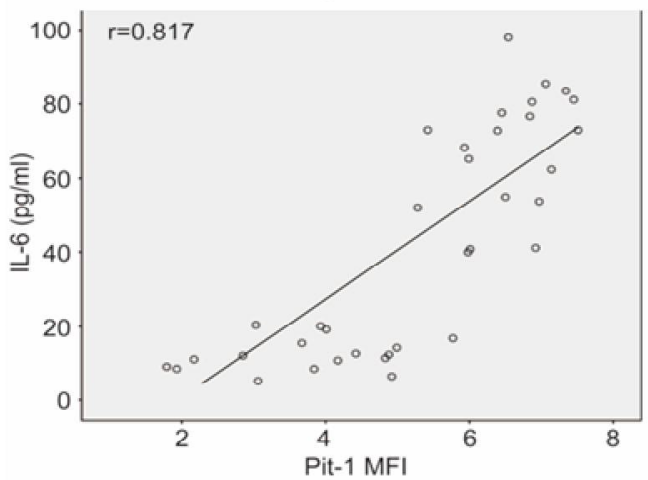

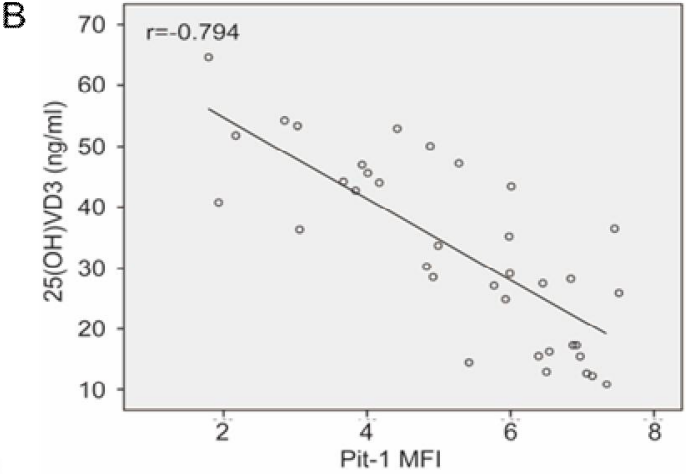

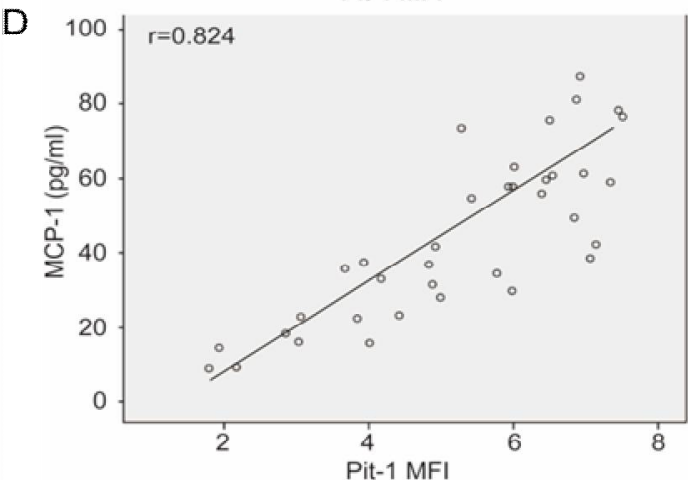

Figure 2: Spearman correlation of Pit-1 expression and concentration of CRP $(A), 25(\mathrm{OH}) \mathrm{D}_{3}(\mathrm{~B})$, IL-6 (C), MCP-1 (D) in DNU group

A

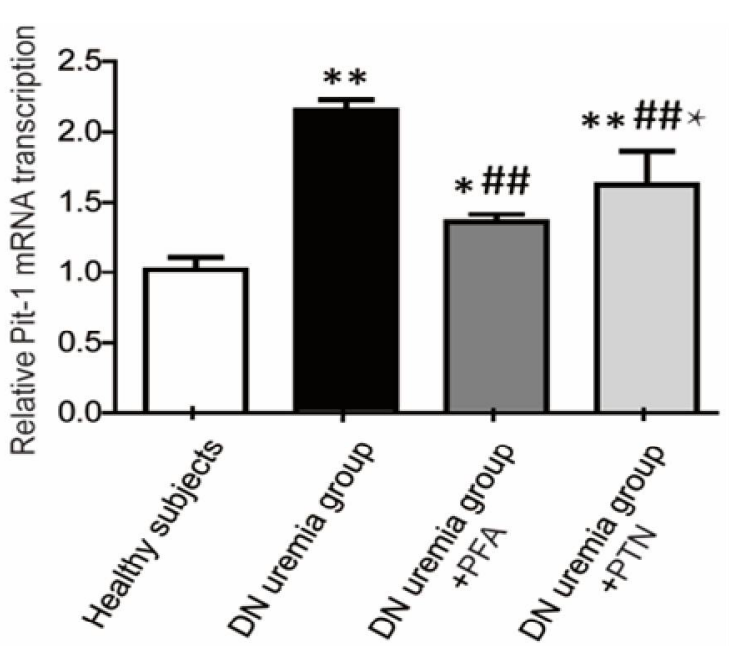

$\mathrm{B}$

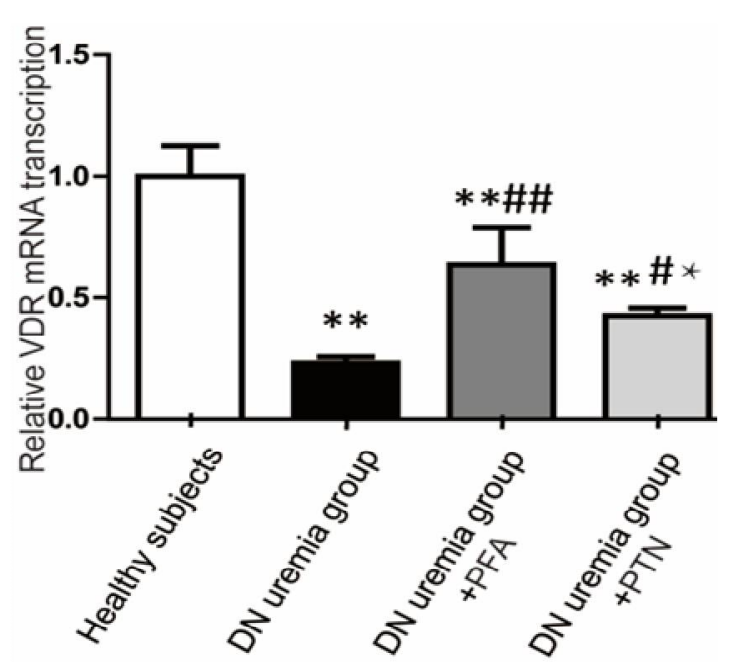

Figure 3: Expression level of Pit-1 (A) and VDR (B) measured by qRT-PCR in THP-1 monocytes treated with serum from different groups; ${ }^{*} p<0.05$, ${ }^{* *} p<0.01$ vs. healthy subjects; $\# P<0.05$, \#\# $P<$ 0.01 vs. DNU group; ${ }^{*} p<0.05$ vs. DNU group + PFA

inflammation, MCP-1 and IL-6 were measured by ELISA in THP-1 after PFA and PTN treatments.

Figure 5A shows that IL- 6 in THP-1 monocytes was higher in patients of DNU group (89.96 \pm 9.8 $\mathrm{pg} / \mathrm{mL}, p<0.01)$, PFA treated group (55.38 \pm $3.22 \mathrm{pg} / \mathrm{mL}, p<0.01$ ) and PTN treated group $(68.68 \pm 6.01 \mathrm{pg} / \mathrm{mL}, p<0.01)$, when compared to healthy control $(14.15 \pm 2.72 \mathrm{pg} / \mathrm{mL})$. On the other hand, MCP-1 levels in Figure 5B were comparable to that of IL-6 (healthy subjects
$24.49 \pm 2.43 \mathrm{pg} / \mathrm{mL} ;$ PFA-treated group $39.67 \pm$ $3.62 \mathrm{pg} / \mathrm{mL}, p<0.01$; PTN-treated group $52.62 \pm$ $5.00 \mathrm{pg} / \mathrm{mL}, p<0.01$; DNU group, $63.67 \pm 5.86$ $\mathrm{pg} / \mathrm{mL}, p<0.01$ ), indicating that PFA and PTN effectively decreased the level of inflammatory cytokines, when compared with the levels in DNU group. Interestingly, PFA treatment effectively decreased IL- 6 when compared with PTN group, suggesting that the effect of PFA was much more effective than that of PTN. 
A

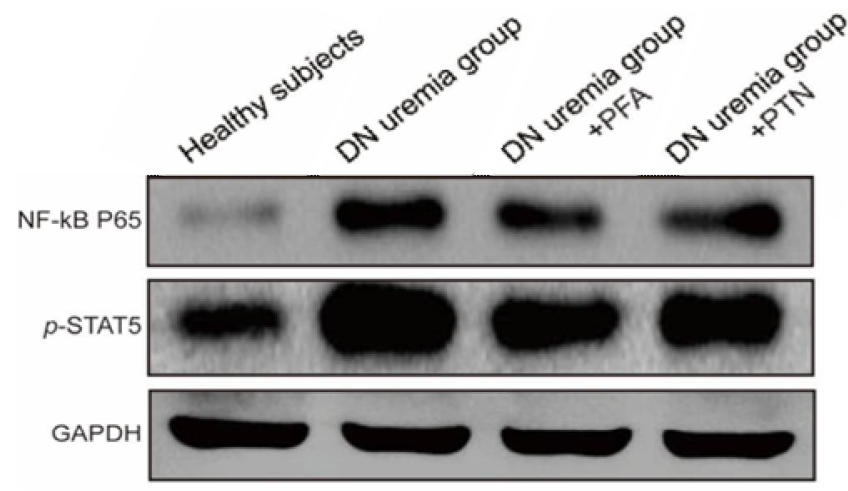

B

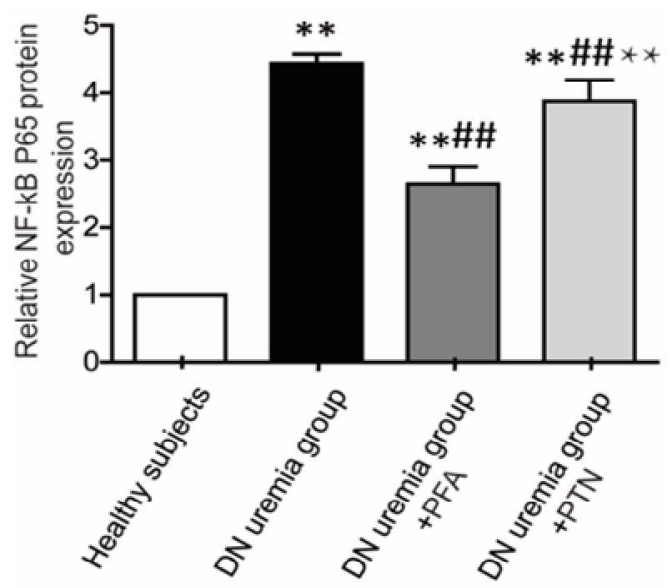

C

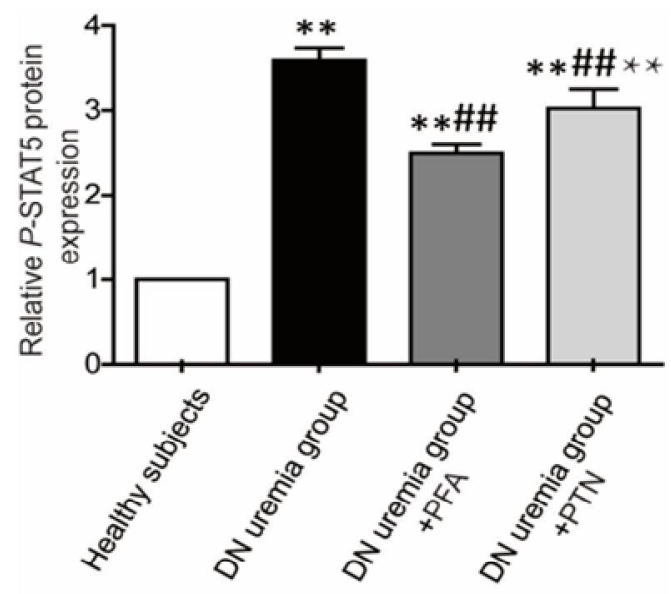

Figure 4: Phosphorylation level of NF-KB p65 and pSTAT5. (A) NF-KB p65 and p-STAT5 on THP-1 from four groups, GAPDH was used as internal control; $(B)$ and $(C)$ represent histogram of NF-kB p65 and $p$-STAT5, respectively; ${ }^{* *} p<0.01$ vs. healthy subjects; ${ }^{\# \# ~} P<0.01$ vs. DNU group; ${ }^{* *} p<0.01$ vs. DNU group + PFA

A

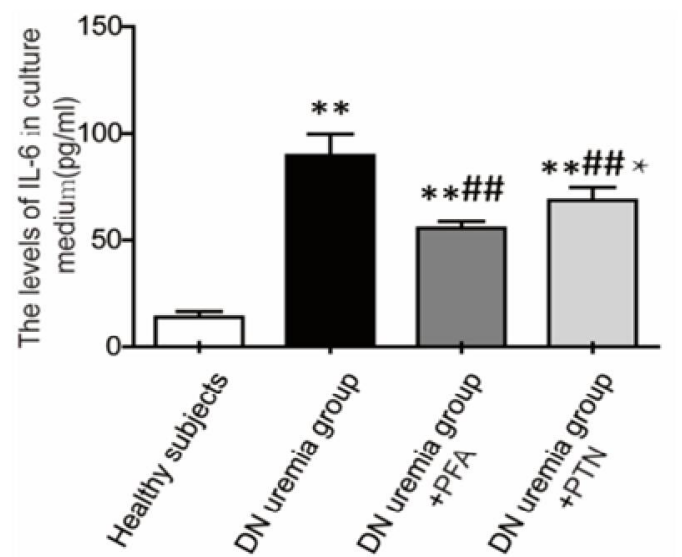

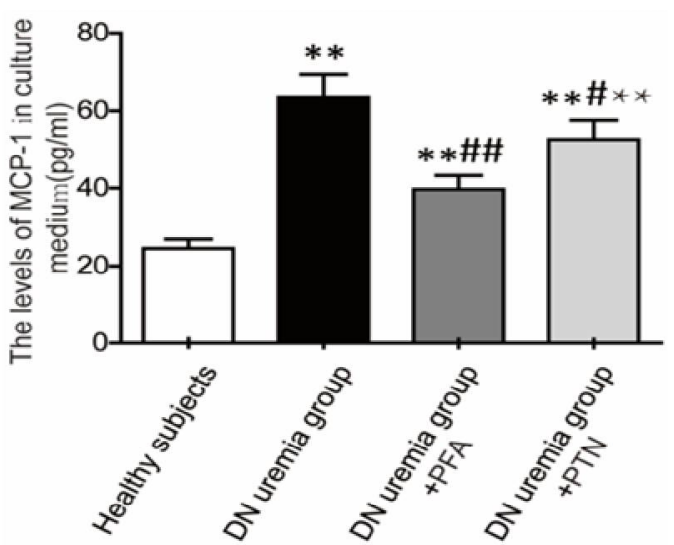

Figure 5: Levels of inflammation related factors in THP-1 cells IL-6 (A) and MCP-1 (B) in the 4 groups; ${ }^{*} p<0.05,{ }^{* *} p<0.01 \mathrm{vs}$. healthy subjects; \#\#P<0.01 vs. DNU group; ${ }^{*} p<0.05,{ }^{*} p<0.01$ vs. DNU group + PFA

\section{DISCUSSION}

The aim of this study was to find out if the expression of Pit-1 was associated with inflammation in DN uremia patients. The variation in levels of NF-KB and STAT5 expression products as observed in this study indicates that PFA and PTN inhibited local inflammation by blocking Pit-1. It has been proposed that inflammation is a biological process that contributes to DNU pathogenesis [3]. Recent studies have demonstrated that monocytes play an essential role in the onset of glomerulopathy and pathogenesis of tubulointerstitial lesions associated with DN $[12,13]$. The relationship between monocytes and 
Pit-1 expression from DNU patients has been hardly reported. In this study, $\mathrm{CD} 14^{+} \mathrm{CD} 16^{+}$, a pro-inflammatory monocyte subpopulation, increased and Pit-1 in monocytes exhibited an up-regulated expression in DNU patients, which strongly indicates that Pit-1 may be involved in the aberrant immune activation present in DNU patients.

As is already established, CRP, the acute phase reactive protein induced by cytokines, is a sensitive indicator of the degree of inflammatory. IL-6 and MCP-1 are important inflammatory cytokines. In addition, it has been reported that low levels of $25(\mathrm{OH}) \mathrm{D}_{3}$ and VD receptor (VDR) may be involved in the genesis of the complications that occur in DM [14]. This study demonstrated that Pit-1 expression is in positive correlation with MCP-1 concentration suggesting that Pit-1 is associated with monocytes dysfunction involved in inflammation and pathogenesis of DNU.

Some of functions of THP-1 monocytes are similar to those of normal human monocytes. Thus it is used to simulate human peripheral blood monocytes in vitro $[15,16]$. In this study, THP-1 was used to replace PBMCs. PFA, an organic analogue of phosphate, is a competitive inhibitor of Pit-1. Previous studies have showed that PFA can block expression of OPN and Cbfa1, two ossification markers of VSMC induced by high phosphorus, when phosphorus uptake is inhibited [17]. PTN, an inhibitor of NF$K B$, could inhibit the systemic inflammation process. Earlier studies have confirmed that PTN could relieve the clinical and pathologic conditions associated with $\mathrm{DN}$ in $\mathrm{db} / \mathrm{db}$ model, as well as decrease the inflammatory factors such as MCP-1 and IL-6 $[18,19]$. The findings of this study show that the inflammatory factors examined were extremely sensitive to PFA and PTN, as evidenced by the significant reduction of MCP-1 and IL-6 levels in THP-1, as well as the severe intracellular inactivation of p-STAT5 and NF-KB p65 pathways in DNU patients. These results suggests that NF-KB and STAT5 signaling are important in the pathogenesis of DNU. Expression of Pit-1, NF-KB and STAT, as well as sensitive reaction by inflammatory cytokines in monocytes are useful for the treatment and prevention of DNU. It is reported that NF-KB, defined as a hinge involved in regulating genes expression, could induce increases in the production of inflammatory cytokines. In the present study, PFA and PTN also caused decreases in MCP-1 and IL-6 levels, which is an indication that PFA and PTN suppressed activities of NF-KB and STAT5 via the inhibition of Pit-1.
Pit-1 was previously reported to be required for $\mathrm{Pi}$-induced osteogenic differentiation and calcification of VSMCs [20]. Furthermore, Pit-1 mRNA was shown to be up-regulated in uremic rat aorta with resultant severe hyperphosphatemia [21]. In this study, it was found that inflammatory cytokine expressions and phosphorylation of NF-KB p65 and PSTAT decreased significantly with attendant inhibition of Pit-1. This shows that Pit-1was involved the activation of NF-KB and STAT pathways. Thus Pit-1 participates in monocyte inflammation in DNU patients. This fact, combined with the finding that PFA and PTN treatment inhibited the increase in Pit-1, is suggestive of a possible interaction between Pit-1 and the NF-KB and STAT5 pathways in the course of inflammation. The decreases in IL- 6 and MCP- 1 associated with PFA and PTN proved that the protective effect of PFA and PTN on inflammation contributes to the suppression of PSTAT5 and NF-kB p65 production. Thus, Pit-1 can be employed as a new target for treatment of DNUinduced inflammation. Therefore, a thorough understanding of the interaction between Pit-1 and the NF-KB and STAT5 pathways may provide a novel approach to the management of inflammation in DNU patients.

\section{CONCLUSION}

The findings of this study suggest that suppression of Pit-1 by PFA and PTN treatment attenuated the inflammation of monocytes in uremic DN patients by regulating the phosphorylation of NF-KB p65 and pSTAT5. These findings may provide new insight into how other therapeutic strategies can be developed for the prevention and/or management of inflammation in DNU patients.

\section{DECLARATIONS}

\section{Acknowledgement}

None declared.

\section{Conflict of Interest}

No conflict of interest associated with this work.

\section{Contribution of Authors}

The authors declare that this work was done by the authors named in this article and all liabilities pertaining to claims relating to the content of this article will be borne by them. 


\section{Open Access}

This is an Open Access article that uses a funding model which does not charge readers or their institutions for access and distributed under the terms of the Creative Commons Attribution License (http://creativecommons.org/licenses/by/ 4.0) and the Budapest Open Access Initiative (http://www.budapestopenaccessinitiative.org/rea d), which permit unrestricted use, distribution, and reproduction in any medium, provided the original work is properly credited.

\section{REFERENCES}

1. Cooper ME. Is diabetic nephropathy disappearing from clinical practice? Pediatr Diabetes 2006; 7(5): 237-238.

2. Jorsal A, Tarnow L, Lajer M, Ek J, Hansen T, Pedersen $\mathrm{O}$, Parving $\mathrm{HH}$. The PPAR gamma 2 Pro12Ala variant predicts ESRD and mortality in patients with type 1 diabetes and diabetic nephropathy. Mol Genet Metab 2008; 94(3): 347-351.

3. Donath MY, Shoelson SE. Type 2 diabetes as an inflammatory disease. Nat Rev Immunol 2011; 11(2): 98-107.

4. Jagannathan-Bogdan $M$, McDonnell ME, Shin $H$, Rehman Q, Hasturk H, Apovian CM, Nikolajczyk BS. Elevated proinflammatory cytokine production by a skewed $T$ cell compartment requires monocytes and promotes inflammation in type 2 diabetes. $J$ Immunol 2011; 186(2): 1162-1172.

5. Yang $M$, Gan $H$, Shen $Q$, Tang $W$, Du X, Chen $D$. Proinflammatory $C D 14+C D 16+$ monocytes are associated with microinflammation in patients with type 2 diabetes mellitus and diabetic nephropathy uremia. Inflammation 2012; 35(1): 388-396.

6. Tatsumi S, Segawa $H$, Morita K, Haga $H$, Kouda $T$, Yamamoto $H$, Inoue $Y$, Nii T, Katai K, Taketani $Y$, et al. Molecular cloning and hormone regulation of Pit-1, a sodium-dependent phosphate cotransporter from rat parathyroid glands. Endocrinology 1998; 139(4): 16921699.

7. Lau WL, Pai A, Moe SM, Giachelli CM. Direct effects of phosphate on vascular cell function. Adv Chronic Kidney Dis 2011; 18(2): 105-112.

8. Alberti K.G.M.M., Zimmet P.Z. for the WHO consultation. Definition, diagnosis and classification of diabetes mellitus and its complications. Part 1: diagnosis and classification of diabetes mellitus provisional report of a WHO consultation. Diabet. Med. 1998; 15: 539-553.
9. KDOQI clinical practice guideline for diabetes and chronic kidney disease. Am J Kidney Dis. 2012; 60(5): 850-886.

10. Williams JR. Revising the Declaration of Helsinki. World Med. J. 2008; 54:120-122

11. Vallabhapurapu S, Karin M. Regulation and function of NF-kappaB transcription factors in the immune system. Annu Rev Immunol 2009; 27: 693-733.

12. Ruster C, Wolf $G$. The role of chemokines and chemokine receptors in diabetic nephropathy. Front Biosci 2008; 13: 944-955.

13. Chow F, Ozols E, Nikolic-Paterson DJ, Atkins RC, Tesch $\mathrm{GH}$. Macrophages in mouse type 2 diabetic nephropathy: correlation with diabetic state and progressive renal injury. Kidney Int 2004; 65(1): 116128.

14. Stubbs JR, Idiculla A, Slusser J, Menard R, Quarles LD. Cholecalciferol supplementation alters calcitriolresponsive moncyte proteins and decreases inflammatory cytokines in ESRD. J Am Soc Nephrol 2010; 21(2): 353-361.

15. Reddy PV, Puri RV, Khera A, Tyagi AK. Survival and pathogenesis of mycrbacterium tuberculosis in THP-1 macrophages and the guinea pig model of infection. $J$ Baceriol 2012; 194(3): 567-575.

16. Marcil V, Lavoie JC, Emonnot L, Seidman E, Levy E. Analysis of the effects of iron and vitamin $C$ cosupplementation on oxidative damage, antioxidant response and inflammation in THP-1 macrophages. Clin Biochem 2011; 44(10-11): 873-883.

17. Jono $S$, Shioi $A$, Ikari $Y$, Nishizawa $Y$. Vascular calcification in chronic kidney disease. J Bone Miner Metab 2006; 24(2): 176-181.

18. Juliana $C$, Fernandes-Alnemri $T$, Wu J, Datta $P$, Solorzano L, Yu JW, Meng R, Quong AA, Latz E, Scott $C P$, Alnemri ES. Anti-inflammatory compounds parthenolide and bay 11-7082 are direct inhibitors of the inflammasome. J Biol Chem 2010; 285(13): 9792-9802.

19. Mathema VB, Koh YS, Thakuri BC, Sillanpaa $M$. Parthenolide, a sesquiterpene lactone, expresses mutiple anti-cancer and anti-inflammaory activities. Inflammation 2012; 35(2): 560-565.

20. Li X, Yang HY, Giachelli CM. Role of the sodiumdependent phosphate cotransporter, Pit-1, in vaxcular smooth muscle cell calcification. Circ Res 2006; 98(7): 905-912.

21. Mizobuchi $M$, Ogata $H$, Hatamura I, Koiwa $F$, Saji $F$, Shiizaki K, Neqi S, Kinugasa E, Ooshima A, Koshikawa $S$, et al. Up-regulation of Cbfa1 and Pit-1 in calcified artery of uraemic rats with severe hyperphosphataemia and secondary hyperparathyroidism. Nephrol Dial Transplant 2006; 21(4): 911-916. 